\title{
Tari Rampoe sebagai Cerminan Karakteristik Masyarakat Aceh
}

\author{
Rika Restela, Tati Narawati \\ Universitas Pendidikan Indonesia (UPI) Bandung \\ Jalan Setiabudi no. 229 Bandung 40154
}

\begin{abstract}
This article is a study of ethnochoreology wich is combined with sociology and folklore, and used to analyze Rampoe dance that consists of five Aceh dances namely, Seudati, Pho, Laweut, Ratoh Duek and Saman. The objective of this study is to reveal the characteristics of the Acehnese and its associations between traditional governance structure (sultan, ulama, ulleebalang), and leadership in the dance (syekh, aneuksyahi, apiet), as well as the relation of social order pattern with the essence of poetry and movements of Rampoe dance. So it needs a sharp analysis of the text and the contexts of dance. The result of this qualitative research are: (1) The form of leadership in the dance is adopted from traditional administration system:, (2) The nature of Acehnese attitudes that include assertiveness, high self esteem, cohesiveness, loyalty, uphold the brotherhood values, and never give up is expressed in the essential movements and lyrics of the Rampoe dance.
\end{abstract}

Keywords: rampoe dance, etnochoreology, Acehnese characteristics

\begin{abstract}
ABSTRAK
Artikel ini adalah kajian Etnokoreologi yang dipadu dengan sosiologi dan folklore yang digunakan untuk menganalisis tari Rampoe yang merupakan tarian kolektif dari lima tarian Aceh, yaitu Seudati, Pho, Laweut, Ratoh Duek dan Saman. Tujuan penelitian ini untuk mengungkapkan karakteristik masyarakat Aceh serta keterkaitannya antara struktur pemerintahan adat dan kepemimpinan dalam tari, serta keterkaitan antara pola tatanan masyarakat dan esensi syair maupun gerak tari Rampoe. Untuk itu dibutuhkan analisis yang tajam terhadap teks dan konteks pada tarinya. Penelitian kualitatif ini, membuktikan hasil, bahwa: (1) bentuk kepemimpinan tari diadopsi dari pemerintahan adat, (2) sifat masyarakat Aceh yang tegas, memiliki harga diri yang tinggi, kompak, setia kawan, menjunjung nilai-nilai persaudaraan, dan pantang menyerah, tercermin dalam esensi gerak dan syair pada tari Rampoe.
\end{abstract}

Kata kunci: tari rampoe, etnokoreologi, karakteristik masyarakat Aceh 


\section{PENDAHULUAN}

Karakteristik sebuah masyarakat dapat ditelusuri pada salah satu cabang seninya, yaitu tari yang merupakan salah satu pernyataan budaya. Oleh karena itu, maka sifat, gaya, dan fungsi tari selalu tidak dapat dilepaskan dari kebudayaan yang menghasilkannya (Edi Sedyawati, 1986:3). Selanjutnya, Dibia (2007:14) menjelaskan bahwa selain mengandung pesan-pesan tertentu (naratif, simbolik, kinestetik), sajian tari selalu dipengaruhi bahkan dipolakan oleh nilai-nilai atau konsep seni dan budaya kelompok etnis yang melahirkannya. Berdasarkan pernyataan tersebut, dapat disimpulkan bahwa terbentuknya sebuah tari tidak lepas dari masyarakat pemiliknya. Dengan demikian tari merupakan sebuah cerminan bagi lingkungan budaya dan karakteristik sekelompok masyarakat asalnya. Sejalan dengan pendapat di atas, tari di daerah Aceh memiliki ciri khas tersendiri yang berasal dari karakteristik masyarakat berupa struktur adat, tingkah laku, dan pola pikir yang tertuang dalam sebuah bentuk tari, yang kemudian merupakan identitas dan produk nyata dari masyarakat pemiliknya. Salah satu jenis tari yang menggambarkan karakteristik dari masyarakat Aceh adalah tari rampoe.

Tari rampoe adalah pertunjukan dari kumpulan beberapa tarian Aceh yaitu Seudati, Pho, Laweut, Ratoeh duek, dan Saman. Kelima tarian yang diramu menjadi sebuah kesatuan pertunjukan ini selain mengandung pesan dakwah dan moral, juga sangat mewakili gambaran karakteristik masyarakat Aceh, yaitu Islami, heroik, kompak, tegas, kukuh, berani, pantang menyerah, dan memiliki nilai sosial yang tinggi.

Pada abad XVI, agama Islam berkembang pesat di daerah Aceh. Pengaruh Islam sangat jelas terlihat dalam sistem politik, aturan adat, hubungan masyarakat, dan struktur pemerintahannya. Ada beberapa kitab yang dikarang oleh ulama-ulama ter- kenal di Aceh, yang dijadikan rujukan oleh pemerintah dan sistem politik Aceh, seperti kitab Taj al-Salatin, Bustan al-Salatin, serta Tadhkirat al-Raddikin. Shaikh Abbas Ibnu Muhammad (Teungku Chik Kutakarang) menulis dalam kitab Tadhkirat al-Radikin yang dikutip oleh Alfian (1987:38) bahwa "Adat ban adat hukom ban hukom, adat ngon hukom sama kembar, tatkala mufakat adat ngon hukum, nanggroe seunang hana goga" artinya: "Adat menurut adat, hukum syariat menurut hukum syariat, adat dengan hukum syariat sama kembar, tatkala mufakat adat dengan hukum itu, negeri senang tiada huru hara". Selanjutnya, dalam kitab Thadkirat al-Radikin disebutkan bahwa dalam dunia ini ada tiga jenis raja, yaitu : (1) raja yang memegang jabatan lahir saja, yang memerintah rakyat menurut hukum adat kebiasaan dunia; (2) raja yang memegang hukum batin yang memerintah berdasarkan jalan agama yaitu ahl al-syari'ah; dan (3) rasul dan nabi-nabi. Apa yang diperintahkan oleh raja jenis pertama harus ditaati, jika perintah itu bersatu dengan ajaran agama (Alfian, 1987:38).

Apabila dilihat dari uraian Syaikh Abbas Ibnu Muhammad yang menjadi pedoman dalam struktur pemerintahan Aceh, masyarakat Aceh sangat menjunjung tinggi akan nilai-nilai kepemimpinan, sehingga rakyat Aceh patuh akan aturan yang telah ditetapkan oleh pemimpinnya bila sejalan dengan hukum syariat. Ada beberapa status lembaga pemerintahan tertinggi di Aceh, yaitu (1) Tuanku Sultan; (2) Uleebalang; dan (3) Ulama (Ahmad, 2007:24). Pemegang kekuasaan tertinggi adalah seorang sultan sebagai pengendali daerah kesultanan Aceh. Uleebalang adalah raja-raja kecil yang berasal dari beberapa daerah atau mukim. Sultan dan Uleebalang digolongkan sebagai pemimpin adat. Di bawah Uleebalang yang juga termasuk ke golongan pemimpin adat, ada juga Geuchik-geuchik (kepala kampung), Teungku Imeum (Imam madrasah), dan Ure- 
ung tuha atau Tuha Peut yang menjadi bagian kepala kampung sebagai penghubung antara rakyat dengan Uleebalang.

Pada tari rampoe juga terdapat tiga tokoh kepemimpinan, yaitu Syekh, Aneuk syahi, dan Apiet. Syekh merupakan seorang pemimpin yang mengatur jalannya pertunjukan tari. Syekh berperan sebagai orang yang mengarahkan gerak dan barisan pola dalam sebuah pertunjukan tari. Aneuk syahi adalah seseorang yang melantunkan syair untuk mengiringi tarian. Apiet adalah seseorang yang membantu Syekh dalam mengarahkan geraknya.

Apabila diperhatikan antara jejak-jejak sistem pemerintahan lama dan observasi terhadap tarian Aceh, terdapat adanya persamaan tiga tokoh pemimpin tari, sehingga menimbulkan pertanyaan: adakah keterkaitan antara struktur pemerintahan adat dan sistem kepemimpinan yang ada di dalam tarian Aceh?

Selain struktur pemerintahan tradisional, sistem tatanan masyarakat Aceh juga tidak lepas dari pengaruh nilai-nilai ajaran agama Islam. Kedudukan agama sangat mendominasi pada kehidupan masyarakat Aceh. Nilai-nilai agama Islam sangat terlihat pada setiap aktivitas masyarakat, baik dalam bidang seni budaya maupun dalam adat istiadatnya. Hal ini dilandasi oleh masuknya agama Islam yang diiringi oleh banyaknya ulama dan pedagang dari Gujarat, Arab, dan Persia yang berdatangan ke berbagai wilayah di daerah Aceh. Mereka bertujuan untuk berdagang serta menyebarkan ajaran agama Islam, salah satunya dengan media kesenian. Melalui kesenian para ulama menyampaikan pesan-pesan moral, dakwah, dan syiar agama sehingga hampir setiap gerak dan syair-syair yang mengiringi tarian Aceh merupakan lafal syahadat dan syalawat. Hermaliza, dkk. (2014:2) memaparkan bahwa eksistensi tari tradisi Aceh yang bersifat menyebarkan dakwah dan bersifat komunal merupakan representasi dan nilai-nilai sosial budaya masyarakat yang tumbuh dan berkembang hingga saat ini. Maka tidak heran jika ditemukan adanya karakteristik masyarakat Aceh yang agamis dan memiliki sikap kekerabatan satu sama lain.

Pada umumnya, tarian Aceh dimainkan oleh beberapa orang atau kelompok. Jika dianalisis lebih dalam pada maknanya, masyarakat Aceh adalah masyarakat yang menjaga nilai solidaritas, kekompakan, dan kebersamaan dalam kelompoknya. Ketenteraman, keseimbangan, keamanan, dan kedamaian merupakan hal-hal yang sangat menentukan dalam kehidupan masyarakat Aceh. Mereka selalu berupaya menghormati nilai-nilai yang telah disepakati bersama dan aturan yang telah ditetapkan oleh agama (Kurdi, 2005:36).

Pada penelitian ini, peneliti akan menganalisis tari rampoe lebih dalam mencakup bentuk tari tersebut dengan kajian etnokoreologi untuk menemukan karakteristik masyarakat sebagai pendukungnya, yangmeliputi struktur pemerintahan adat dan pola tatanan masyarakat Aceh. Pendekatan etnokoreologi dipilih karena disiplin ilmu ini merupakan penyempurnaan dari semua disiplin ilmu terdahulu seperti antropologi tari, etnologi tari, sosiologi, koreologi, etnokoreografi, dan sebagainya untuk mengkaji sebuah tari etnis baik secara tekstual maupun secara kontekstual. Pendekatan etnokoreologi merupakan pendekatan multidisiplin, dianggap dapat memberikan kontribusi pada penelitian ini yang akan menganalisis tari rampoe dengan pengumpulan data yang beragam sehingga kajian etnokoreologi dapat mengupas lapis-lapis komponen sosial budaya yang meliputi sejarah, struktur sosial masyarakat, esensi gerak tari, nilai budaya, serta entitas kebudayaan etnik yang terbingkai dalam sebuah karya tari. 


\section{METODE}

Penelitian ini menggunakan pendekatan kualitatif dan metode analisis deskriptif, yaitu penelitian yang dilakukan dengan cara pendekatan terhadap objek yang diteliti, menemukan sumber-sumber yang benar dan akurat untuk memperoleh data, baik melalui observasi dan wawancara, kemudian dideskripsikan secara sistematis. Hal ini sejalan dengan pemaparan dari Malik dan Hamid (2014:182) bahwa, "research methods based on emergent paradigm are predominantly qualitative which use the technique on interviewing, observation and data collection through (mostly) fieldwork".

Berdasarkan cara mengumpulkannya, data dapat dibedakan menjadi data primer dan data sekunder. Data primer merupakan data yang diperoleh langsung dari sumber data penelitian (responden). Data sekunder diperoleh dari dokumen, publikasi, artinya data sudah dalam bentuk jadi (Wirartha, 2006:35). Pada penelitian, data diambil langsung secara primer dari lapangan, yaitu Sanggar Pusaka Nek Leuen, dengan narasumber Syaifuddin yang berdomisili di Kota Langsa, Aceh. Selanjutnya, data juga akan diambil secara sekunder yaitu melalui proses studi kepustakaan yang akan menunjang dan melengkapi data pada penelitian ini.

\section{HASIL DAN PEMBAHASAN}

\section{Tari Rampoe pada Masyarakat Aceh}

Penyebaran Islam di Aceh sering menggunakan media kesenian yaitu karya sastra, tari, syair, dan musik untuk mempermudah penyebaran dakwah dan nilai-nilai akhlak serta akidah terhadap masyarakatnya. Dengan kata lain, para ulama menggunakan media kesenian untuk menarik perhatian masyarakat untuk mempelajari agama Islam. Dari beberapa media kesenian tersebut, seni tari merupakan seni yang paling menonjol keikutsertaannya dalam syiar agama melalui gerak dan syair yang mengiringinya. Ada beberapa tari yang digunakan sebagai media syiar agama, yaitu Seudati, Rappa'i geleng, Saman, Laweut, Rateb, Meusekat, dan lain-lain.

Pada konteks sebagai manifestasi dan representasi budaya Aceh, tari terpola dari sebuah sistem pelembagaan masyarakat yang sesuai dengan semangat tradisi di zamannya. Semangat tersebut, terpola dan tersusun dalam struktur tekstual dan kontekstual, yang terproses dari bentuk karakteristik, identitas, simbol pada masyarakat Aceh. Rohidi (2011:53) memaparkan bahwa seni disebut ekstraestetik yang terkandung dalam latar budaya dari kehidupan penciptanya (masyarakat) yang merupakan kristalisasi nilai kehidupan sosio-budaya dalam bentuk nilai-nilai, pengetahuan, kepercayaan, dan lingkungan. Sejalan dengan pendapat tersebut, Soemaryatmi (2010:3) menjelaskan bahwa tari sebagai wujud budaya aktivitas masyarakat yang berhubungan dengan realita sosial, di dalamnya juga terkandung esensi dan nilai yang merefleksikan kepribadian masyarakat asalnya. Artinya, bentuk pada tari merupakan cerminan tingkah laku, pola pikir, dan adat-istiadat dari masyarakat asalnya karena tari merupakan produk ekspresi masyarakat. Maka, tari merupakan identitas budaya yang menggambarkan ciri khas dari asalnya yaitu masyarakat. Salah satu produk seni masyarakat Aceh yang merupakan refleksi dari karakteristik dan identitasnya adalah tari Rampoe.

Tari Rampoe terdiri dari lima tarian yang sering disebut sebagai babak pada tari (khusus Rampoe), yaitu Seudati, Pho, Laweut, Ratoeh duek, dan Saman. Tari Rampoe mulai berkembang sejak tahun 1980, yang diciptakan oleh sekelompok seniman Aceh yang bertempat tinggal di Kota Langsa yaitu: Syech Lah Geunta, Syech Ampon Mae dari Aceh Utara, Tarmizi, dan Syaifuddin dari Bireun. Berdasarkan wawancara dengan narasumber, awalnya tarian ini diciptakan 
untuk pembukaan acara nasional yang dihadiri oleh beberapa koreografer Indonesia seperti Nungki Kusumastuti, Marzuki Hasan, dan Nurdin Daud dari IKJ. Mereka ingin menampilkan sebuah pertunjukan yang merupakan tarian kolektif dari beberapa tarian Aceh, sehingga dipilihlah beberapa babak dari tari Seudati, Pho, Laweut, Ratoeh duek, dan Saman menjadi sebuah kesatuan pertunjukan yang menggambarkan identitas masyarakat Aceh.

\section{Esensi Gerak Tari Rampoe dan Keterkaitan- nya dengan Karakteristik Masyarakat Aceh}

Supriyanto (2012:1) memaparkan secara tekstual pemberlakuan tari berkaitan dengan bentuk, struktur, dan gaya tarinya. Secara kontekstual, pemberlakuan tari sebagai teks kebudayaan, dapat ditelaah melalui kedudukannya di masa sekarang kaitannya dengan catatan yang ada di masa lampau. Berdasarkan pernyataan tersebut, penelitian ini menggunakan kajian etnokoreologi untuk menemukan jawaban dari rumusan masalah mengenai konteks dan teks tari rampoe. Mengingat Marco de Marinis dalam Narawati (2007:76) menyebutkan bahwa bentuk seni pertunjukan memiliki multylayered entity (kesatuan multilapis), sehingga dalam mengkaji setiap lapisnya memerlukan konsep dan teori lain yang berorientasi pada dance studies.

Ada beberapa ragam gerak khas yang selalu muncul dalam setiap babak pada tari Rampoe. Secara etnokoreologis, apabila diamati ragam gerak pada tari dapat diklasifikasikan berdasarkan kategorisasi gerak. Narawati (2009:20) mengutarakan secara tekstual Etnokoreologi memiliki empat kategori gerak yang selalu digunakan dalam sebuah komposisi tari, yaitu gerak berpindah tempat (locomotion movement), gerak murni (pure movement), gerak maknawi (gesture), dan penguat ekspresi (baton signal). Di bawah ini akan dipaparkan karakteristik setiap babak dari hasil klasifikasi ra- gam gerak yang terdapat pada tari Rampoe berdasarkan tiga kategorisasi, urutan babak dalam bentuk penyajiannya, dan keterkaitannya dengan karakteristik masyarakat Aceh yang meliputi tingkah laku dan pola tatanan masyarakatnya, yaitu:

a. Karakteristik masyarakat Aceh dalam esensi ragam gerak dan syair babak Seudati dan Laweut.

\begin{tabular}{|c|c|c|c|}
\hline No & $\begin{array}{l}\text { Nama } \\
\text { gerak }\end{array}$ & $\begin{array}{l}\text { Kategori } \\
\text { gerak }\end{array}$ & $\begin{array}{l}\text { Analisis } \\
\text { Gerak }\end{array}$ \\
\hline 1. & $\begin{array}{l}\text { Saleum } \\
\text { (salam) }\end{array}$ & Gesture & $\begin{array}{l}\text {-Terdapat } 7 \text { ges- } \\
\text { ture, } 4 \text { pure move- }\end{array}$ \\
\hline 2. & $\begin{array}{l}\text { Geddhan } \\
\text { ghaki } \\
\text { (menghen- } \\
\text { takkan } \\
\text { kaki) }\end{array}$ & $\begin{array}{l}\text { Pure move- } \\
\text { ment }\end{array}$ & $\begin{array}{l}\text { ment, } 1 \text { locomo- } \\
\text { tion. } \\
\text {-Karakteristik } \\
\text { tari terletak pada } \\
\text { gesture. }\end{array}$ \\
\hline 3. & $\begin{array}{l}\text { Keupak si- } \\
\text { wah }\end{array}$ & Gesture & $\begin{array}{l}\text {-Masing-masing } \\
\text { gesture memiliki }\end{array}$ \\
\hline 4. & Puta suie & Locomotion & makna yang se- \\
\hline 5. & Kacak & Gesture & cara folklorik \\
\hline 6. & $\begin{array}{l}\text { Sayeup } \\
\text { kleung }\end{array}$ & $\begin{array}{l}\text { Pure move- } \\
\text { ment }\end{array}$ & $\begin{array}{l}\text { berisi nilai-nilai } \\
\text { masyarakat }\end{array}$ \\
\hline 7. & Poh paha & $\begin{array}{l}\text { Pure move- } \\
\text { ment }\end{array}$ & Aceh. \\
\hline 8. & Kupruk & Gesture & \\
\hline 9. & Nyap & Gesture & \\
\hline 10. & Culek & Gesture & \\
\hline 11. & $\begin{array}{l}\text { Syam ja- } \\
\text { mille }\end{array}$ & Gesture & \\
\hline 12. & Poh dada & $\begin{array}{l}\text { Pure move- } \\
\text { ment }\end{array}$ & \\
\hline 13 & Poh pruet & $\begin{array}{l}\text { Pure move- } \\
\text { ment }\end{array}$ & \\
\hline
\end{tabular}

Sumber: Bagan diadaptasi oleh peneliti

Pada babak Seudati dan Laweut terdapat adanya persamaan makna mengingat jenis penyajian tarian ini termasuk ke dalam rateub deung (babak tari yang dipertunjukan secara berdiri) dan memiliki tema tarian yang sama. Apabila ditelusuri pada maknanya, dapat ditemukan beberapa karakteristik masyarakat Aceh, yaitu: pertama, karakteristik masyarakat Aceh yang memiliki harga diri. Pada babak Seudati terdapat syair yang mengiringi gerak saleum (salam) yaitu, sebagai berikut:

Assalamualaikum warahmatullah, jaroe dua blah ateuh jeumala

Karena saleum nabi keu sunnah, jaroe ta mumat syarat mulia 
(Assalamualaikum warahmatullah, Tangan bersimpuh di atas kepala)

Karena salam disunnahkan oleh nabi, salam dengan berjabat tangan tanda mulia)

Mulia jamee ranub lam puan, mulia rakan mameh suara

(Memuliakan tamu dengan menyajikan sirih Memuliakan tamu dengan menyanyikan suara merdu)

Syair tersebut bermakna permohonan atau penghormatan kepada tamu undangan sebelum memulai pertunjukan tari. Pada syair selanjutnya terdapat kata mulia jamee ranub lam puan, mulia rakan mameh suara, syair ini bermakna bahwa masyarakat Aceh sangat memuliakan tamu yang datang dengan menyajikan sirih sebagai jamuan. Hal ini menggambarkan bahwa membawa buah tangan merupakan hal yang wajib ketika kita akan bertamu ataupun menyambut tamu dalam adat masyarakat sebagai cerminan masyarakat yang ramah.

Makna syair mengajarkan kita untuk mengucapkan salam setiap ingin memulai aktivitas apapun, termasuk sebelum melakukan tarian, agar diberikan kemudahan dan kelancaran. Selain itu, pada syair tersirat makna untuk berperilaku sopan dalam menyambut tamu, dan menjaga silahturahmi dengan mengucapkan sapa terhadap orang lain. Masyarakat Aceh memiliki sifat malu dan harga diri apabila bertamu tidak membawa bungoeng jaroe atau buah tangan. Seperti yang telah dijelaskan oleh Alfian (1987:49), jika orang Aceh ingin mengunjungi Uleebalang daerahnya untuk menyampaikan pengaduan, maka ia akan berusaha membawa sepotong emas untuk mengatasi perasaan takut dan malunya. Rasa harga diri ini sesuai dengan sebuah hadih maja Aceh yang menyebutkan bahwa reut nyang bek, lebeh get meuruah, artinya dari pada tumpah sedikit, lebih baik dituang semua.

Kedua, karakteristik masyarakat Aceh yang hati-hati dan konsisten. Sifat ini dapat dilihat dari ragam gerak langkah, nyap, syam jamille, dan culek. Secara keseluruhan makna dari ragam gerak ini adalah sifat orang Aceh yang selalu berfikir terlebih dahulu sebelum mengambil keputusan, karena mereka selalu mempertimbangkan segala resiko yang akan dihadapinya. Sesuai dengan hadih maja Aceh yang menjelaskan bahwa:

Menyoe tabloe bajee, tauko bak badan droeteu dileea

(kalau membeli baju, ukurlah di badan sendiri dahulu);

Berang kapeu buet tapike dilee, oh ka malee keupeu lom guna

(semua tindakan sebaiknya dipikir dahulu, kalau sudah malu tiada berguna).

Ketiga, ragam gerak Seudati menggambarkan karakteristik orang Aceh yang tegas. Sifat ini dapat ditelusuri dalam gerak keupak groep/keupak siwah (merentangkan kedua tangan seperti sayap), puta suie, poh pruet/paha (memukul perut/paha), geddham ghaki (menghentakkan kaki ke lantai), kacak (gertak), dan kupruk (sayap menyambar) yang membentuk garis-garis simetris. Soedarsono menjelaskan (1986:102) jika garisgaris simetris pada komposisi tari mempunyai watak sederhana, kokoh, dan tenang. Soedarsono (1986:85) juga memaparkan di dalam tari yang terdapat langkah-langkah yang cepat, tegap, dan maskulin memberikan kesan heroik yang menarik. Gerak babak Seudati banyak diadopsi dari tingkah laku elang yang merupakan seekor unggas kuat dan gagah, yang dimanifestasikan dengan langkah-langkah dan gerak tangan yang besar, dengan gerakan cepat, lincah, tangkas, dan gagah. Seperti yang diungkapkan oleh Soedarsono (1986:102), volume gerak tari yang besar dan terbuka mempunyai watak kelaki-lakian, yaitu karakter gagah dan tegap, seperti yang umumnya terdapat pada gerak tari Jawa.

Keempat karakteristik orang Aceh yang pantang menyerah, dapat dilihat pada desain ruang simetris dalam gerak puta suie, keupah siwah, sayeup kleung dan kacak, dimana posisi tangan dan kaki terdiri dari bagian kiri dan kanan yang setangkup. Hal ini sesuai dengan pendapat Murgiyanto (1986:24) bahwa, "dengan keseimbangan yang man- 
tap, desain simetri menghadirkan perasaan yang kokoh, kuat, dan tidak goyah".

Selain itu karakteristik pantang menyerah dapat dilihat pada saat dinamika tari mencapai accelenrando dan crescendo. Murgiyanto (1986:35) menjelaskan bahwa dinamika yang kuat dengan kecepatan sedang terus-menerus dapat memberi kesan yang tegang, sedangkan dinamika yang tajam dengan kecepatan tinggi memberikan kesan merangsang yang diibaratkan seperti semangat untuk tetap berusaha. Dari pendapat di atas apabila dikaitkan dengan karakteristik masyarakat Aceh, maka ditemukan sifat masyarakat yang memiliki energi untuk tetap kokoh dan kuat terhadap pendiriannya.

Sikap pantang menyerah pada masyarakat Aceh yang mempertahankan dan membela agama dapat dilihat dari sebuah tutur hadih maja yang memaparkan bahwa hukom nanggro keupakaian, hukom Tuhan keu kulahkama (hukum negara untuk pakaian, hukum Tuhan untuk Mahkota); ta pageu lampoeh ngon kawat, ta pageu nenggroe ngon adat (pengaman kebun dengan pagar kawat, pengaman negeri dengan adat).

Maknanya adalah hukum pada suatu wilayah atau negara (hukum adat) harus dipergunakan dan dipatuhi, sebagai tata cara dalam menjalani hidup. Hukum Tuhan (agama) adalah pedoman hidup dan wajib dijunjung tinggi lebih dari hukum negara itu sendiri. Hal ini menjadi sebuah landasan dari prinsip orang Aceh yang akan melawan untuk menjaga adat dan agamanya.

b. Karakteristik masyarakat Aceh dalam esensi ragam gerak dan syair babak $P h o$

\begin{tabular}{|c|c|c|c|}
\hline No & $\begin{array}{l}\text { Nama } \\
\text { gerak }\end{array}$ & $\begin{array}{c}\text { Kategori } \\
\text { gerak }\end{array}$ & $\begin{array}{l}\text { Analisis } \\
\text { Gerak }\end{array}$ \\
\hline 1. & $\begin{array}{l}\text { Syuko } \\
\text { (syukur) }\end{array}$ & Gesture & $\begin{array}{l}\text { Manifestasi dari } \\
\text { doa, permohon- } \\
\text { an, dan ucapan } \\
\text { syukur atas nik } \\
\text { mat dan rezeki } \\
\text { yang diberikan } \\
\text { oleh Allah swt. }\end{array}$ \\
\hline
\end{tabular}

Babak Pho berisikan syair-syair yang mengungkapkan rasa syukur terhadap Allah SWT atas nikmat dan karunia yang telah diberikan, sehingga babak ini menggambarkan karakteristik masyarakat Aceh yang religius. Soedarsono (1986:101) menjelaskan bahwa badan manusia dapat dibagi menjadi tiga bagian yang masing-masing mempunyai watak berbeda. Bagian atas terletak dari dada ke atas, merupakan bagian yang berwatak intelektual dan spiritual. Secara komposisi tari, ungkapan-ungkapan yang bersifat intelektual atau spiritual akan lebih fokus apabila dipusatkan pada bagian atas. Lebih khusus lagi dikatakan oleh Sedyawati (1986:15),

"Bahwa gaya tari Aceh memiliki ciri yang khusus yang tidak dimiliki oleh gaya-gaya lain, yaitu gerak-gerak mengayun yang arusnya serba bebas dan arahnya tidak menuju ketitik-titik tertentu yang telah ditetapkan secara ketat tempatnya dalam suatu kerangka bentuk, sehingga gaya gerak tari dijiwai oleh suatu sikap syukur dan memuji kebaikan".

Babak Pho termasuk sebagai babak rateub deung memiliki kesamaan gaya gerak seperti Seudati. Jika dilihat pada gerak babak Pho, terdapat gerak syuko di mana penari duduk bersimpuh mengangkat kepala dan kedua tangan ke atas seperti orang yang hendak berdoa. Pada gerak ini syair yang mengiringi adalah:

Alhamdulillah Allah lon, pujoe ka neubri jaroe ghaki ngon mata

[Puji syukur kepada Allah, sudah diberikan oleh-Nya kaki dan mata]

Juloek-juloekimoen Blang Pidie Tujoeh Pucoek joek getaloe tima

[Betapa dalam sumur di Blang Pidie, tujuh pucuk batang aren tidak bisa digantikan sebagai tali timba]

Pada syair bait pertama, dijelaskan bahwa kita harus selalu bersyukur kepada Allah atas segala nikmat yang telah diberikan. Pada bait kedua, dijelaskan bahwa ada sebuah sumur yang sangat dalam, sehingga tujuh batang kayu yang disatukan apabila dijulurkan tidak dapat mencapai 
dasar sumur. Hal ini mendeskripsikan bahwa nikmat yang Allah beri tidak dapat diukur dengan apapun, sehingga manusia harus senantiasa bertakwa dan bersyukur kepada Allah.

Orang Aceh selalu berupaya dan menghormati aturan-aturan yang telah disepakati bersama atau aturan yang telah ditetapkan agama. Ada hadih maja yang mengatakan "seubakhe-bakhe ureung Atjeh, watee geusebut nan Allah dan Nabi teuiem atawa seungap," artinya sebodoh-bodohnya orang Aceh ketika mendengar nama Allah dan Nabinya mereka terdiam, tak meneruskan pekerjaan yang sedang ia lakukan (Kurdi, 2005:36).

Apabila dikaitkan pada masyarakat, maka ditemukan adanya karakteristik masyarakat Aceh yang religius. Sudah sejak lama Aceh memiliki undang-undang yang mengatur pemerintahan daerah yang berlandaskan dengan Alquran, hadis, ijma', dan qiyas. Selain itu, sejak kecil orang Aceh telah ditanamkan dengan ilmu agama. Pada anak-anak, jika usia telah beranjak lima tahun, maka orang tua akan mengantar mereka ke meunasah untuk belajar mengaji dan mempelajari ilmu agama. Mempersepsikan dirinya sebagai orang Islam merupakan bagian yang telah mengakar dari kehidupan masyarakat Aceh, sehingga kegiatan tersebut telah menjadi tradisi turun temurun.

c. Karakteristik masyarakat Aceh dalam esensi ragam gerak dan syair babak Ratoeh duek dan Saman

\begin{tabular}{|c|c|c|c|}
\hline No & $\begin{array}{l}\text { Nama } \\
\text { gerak }\end{array}$ & $\begin{array}{c}\text { Kategori } \\
\text { gerak }\end{array}$ & $\begin{array}{c}\text { Analisis } \\
\text { Gerak }\end{array}$ \\
\hline 1. & $\begin{array}{l}\text { Teupok ta- } \\
\text { ngan (tepuk } \\
\text { tangan) }\end{array}$ & $\begin{array}{l}\text { Pure move- } \\
\text { ment }\end{array}$ & $\begin{array}{l}\text { - Karakteris- } \\
\text { tik tari terle- } \\
\text { tak pada ges- }\end{array}$ \\
\hline 2. & Poh dada & Pure movement & ture \\
\hline 3. & $\begin{array}{l}\text { Peumat } \\
\text { jaroe (me- } \\
\text { megang } \\
\text { tangan) }\end{array}$ & Gesture & $\begin{array}{l}\text { - Masing-ma- } \\
\text { sing gerak } \\
\text { memiliki } \\
\text { karakteristik }\end{array}$ \\
\hline 4. & $\begin{array}{l}\text { Aseek (ge- } \\
\text { leng ke- } \\
\text { pala) }\end{array}$ & Gesture & $\begin{array}{l}\text { masyarakat } \\
\text { yang kompak } \\
\text { dan religius }\end{array}$ \\
\hline 5. & $\begin{array}{l}\text { Kaloen } \\
\text { ateuh (me- } \\
\text { mandang } \\
\text { ke atas) }\end{array}$ & Gesture & \\
\hline
\end{tabular}

Pertama, karakteristik masyarakat Aceh yang kompak dan setia kawan. Pada babak Ratoeh duek dan Saman banyak ditemukan gerak-gerak yang bentuknya serupa seperti aseek (geleng kepala), poh dada (memukul dada), teupok tangan (tepuk tangan), poh paha (tepuk paha), dheeb (goyang bahu), reuntang (membuka tangan) yang dilakukan dengan komposisi serempak atau alternate (selang-seling). Gerakan dilakukan berulang-ulang dengan dinamika accelenrando (mempercepat tempo) dan cresendo (memperkuat gerak). Gerakan dilakukan berulang-ulang pada dasarnya adalah untuk menjaga kekompakan bersama.

Pada babak Ratoeh duek dan Saman, bentuk gerak banyak memiliki desain-desain garis seperti garis lurus, garis lengkung, garis tegak lurus, dan garis menyilang. Murgiyanto (1986:25) menjelaskan garis tegak lurus pada gerak tari memberikan kesan ketenangan dan keseimbangan, sedangkan garis menyilang atau diagonal memberikan kesan dinamis. Sesuai dengan pendapat tersebut, apabila dianalisis lebih dalam pada makna gerak dan keterkaitannya dengan karakteristiknya, adalah bahwa masyarakat menjaga nilai solidaritas, kekompakan, dan kebersamaan dalam satu kelompok. Makna yang sama juga terdapat pada ragam gerak hai jalla, di mana penari saling peumat jaroe (memegang tangan) dan saling menjaga keseimbangan badan satu sama lain. Pada babak ini juga banyak digunakan komposisi kelompok alternate (selang-seling), misalnya penari bernomor genap berada di atas, sedangkan penari bernomor ganjil berada di bawah. Hal seperti ini menurut Soedarsono menimbulkan kesan perpaduan antara teratur dan menarik, juga kesan antara kesatuan dan terpecah (1986:114). Berdasarkan pernyataan tersebut, ketenteraman, keseimbangan, keamanan, dan kedamaian merupakan hal-hal yang sangat menentukan dalam kehidupan masyarakat Aceh. Maka tidak 
heran apabila banyak ditemukan karakteristik orang Aceh yang setia kawan bahkan memiliki solidaritas tinggi terhadap temannya.

Secara komposisi, hampir semua bentuk tarian Aceh dimainkan secara berkelompok. Hal ini menyiratkan makna bahwa masyarakat Aceh menjunjung tinggi nilai-nilai persatuan. Ada dua tutur hadih maja Aceh yang mengatakan bahwa: Cap di batee lambang di papeun, lagee gata ngon lon kheun hanjeut meutuka (Ada sebuah gambar di batu dan lambang di papan, seperti saya dan kamu tidak bisa dipisahkan); Ureueng Aceh hanjeut teupèh, meunyo ka teupèh bu leubèh han geupeutaba. Meunyo han teupèh, nyawa jeut taraba (Orang Aceh tak boleh tersinggung, jika sudah tersinggung, nasi basi takmau diberikannya. Jika tidak tersinggung, nyawa pun rela diserahkan); Menyoe na ate, pade ta tob, hana bak droe talakee bak gob (kalau memang sudah suka pasti akan diberi, kalau tidak ada, akan dicari).

Makna dari hadih maja ini adalah sebuah bentuk kepedulian atau pengorbanan dari karakteristik orang Aceh, apabila mereka sudah sayang pada seseorang maka apapun akan diusahakan untuk membantunya. Apabila mereka tidak sanggup menyelesaikannya sendiri maka mereka akan mencari cara lain agar tercapai apa yang diiinginkannya.

Kedua, mencerminkan karakteristik masyarakat Aceh yang religius. Ulama menggunakan media syair dan gerak dalam tari untuk mempermudah penyampaian pesan moral dan nasihat kepada masyarakat atau para santri di meunasah (mushola). Setiap penyajian tari yang berbentuk rateub duek (babak duduk), penari duduk bertumpu pada paha dan lutut sebaris berbanjar satu sama lain. Gerak ini menggambarkan seperti shaf dalam sholat. Sikap rateub duek ini juga menggambarkan manusia yang setara dengan lainnya dan menjunjung tinggi kebersamaan.
Soedarsono (1986:106) memaparkan bahwa di dalam komposisi tari terdapat desain atas yang terlukis pada ruang yang berada di atas lantai, menimbulkan kesan artistik dan sentuhan emosional, misalnya desain tinggi yang dibuat pada bagian dari dada penari ke atas. Bagian ini memiliki sentuhan intelektual dan spiritual. Sesuai dengan pendapat tersebut, gerak pada babak ini memiliki makna religius, misalnya (1) gerak kaloen ateuh (kepala diangkat menghadap atas), menimbulkan kontras gerak pada bentuk tubuh penari yang mula-mula dilakukan secara pelan dan kemudian menjadi cepat. Gerakan ini mempunyai makna bahwa kita sebagai manusia harus selalu ingat kepada sang pencipta Allah SWT, (2) gerak aseek (geleng kepala), yaitu gerak memalingkan wajah ke kanan dan ke kiri, menyimbolkan sebuah pengucapan salam dalam mengakhiri ibadah shalat yang dimulai dengan memalingkan wajah ke kanan lalu ke kiri. Gerak aseek juga merupakan manifestasi dari sikap ketika berdzikir di mana kepala bergerak refleks mengikuti irama. Esensi gerak yang telah dijabarkan di atas, mencerminkan bahwa bentuk adat istiadat Aceh selalu beriringan dengan nilai-nilai Islami.

Keterkaitan Jejak Struktur Pemerintahan Adat Aceh dengan Pola Kepemimpinan yang Terdapat pada Tari Rampoe

Pada pertunjukan tari Rampoe terdapat tiga peran penting yang dapat digolongkan sebagai tokoh kepemimpinan di dalam tari, yaitu Syekh, Aneuk syahi, dan Apiet.

a. Peran dan Kedudukan Syekh

Syekh pada tarian Aceh merupakan pemimpin yang mengatur jalannya pertunjukan tari. Syekh berada di posisi tengah dan paling depan di antara pola barisan, baik pola barisan berbanjar atau blah awie (pola belah dua). Peran Syekh sangat menentukan kesuksesan dalam pertunjukan secara keseluruhan. Peran Syekh merupakan gambar- 
an dari adanya konsep imam dan makmum dalam agama Islam.

Selain menjadi seorang leader yang memberikan instruksi, Syekh juga harus dapat mengatur tempo gerakan dari lambat, sedang, cepat, hingga sangat cepat, dan berhenti secara tiba-tiba. Syekh harus mampu mengimbangi tempo gerak dengan lantunan syair yang dinyanyikan oleh Aneuk syahi, sehingga terjadi kolaborasi antar peran masing-masing. Kemampuan lain yang harus dimiliki seorang Syekh adalah mendalami tari secara kontekstual, seperti menguasai kisah-kisah tentang sejarah Aceh, baik dari sisi masa kerajaan, pemerintahan, pembangunan, bahkan pesan-pesan moral dan agama.

Berdasarkan pemaparan tersebut, dapat disimpulkan bahwa menjadi seorang leader atau Syekh tidaklah mudah. Selain karena harus piawai dalam gerak, Syekh dituntut harus cerdas dalam menciptakan syair-syair baru secara spontan dan tanggap terhadap segala kondisi pertunjukan yang relatif berubah-ubah. Syech Lah Geunta seorang maestro Seudati dalam Hermaliza (2014:41) menjelaskan bahwa untuk memenuhi kriteria menjadi seorang Syekh yang mumpuni, dibutuhkan waktu lebih kurang empat tahun agar bisa menjadi Syekh yang siap menghadapi Seudati Tunang (seudati yang dipertandingkan antara beberapa grup). Hal ini tidak lepas dari fatwa bahwa Seudati Tunang merupakan ajang utama dalam menguji kemampuan panggung seorang Syekh. Dengan demikian, menjadi seorang Syekh yang sukses harus memiliki kompetensi khusus yaitu: kharisma yang kuat, gaya menari yang lincah, gerakan yang luwes dan atraktif, serta memiliki karakteristik keacehan yang kental.

\section{b. Peran dan Kedudukan Aneuk syahi}

Syekh juga dibantu oleh Aneuk syahi dan Apeit. Aneuk syahi adalah orang yang melantunkan syair-syair untuk mengiringi tari. Posisi Aneuk syahi biasanya berada di sudut kiri atau kanan belakang pentas, diluar dari barisan Syekh, Apeit, dan penari, namun tetap menjadi suatu kesatuan dalam pertunjukan. Aneuk syahi memiliki beberapa peran penting dalam pertunjukan tari, yaitu sebagai berikut: (1) Aneuk syahi harus mampu mengikuti kecepatan gerak tari dengan irama yang tepat untuk menjaga dinamika gerak para penari; (2) Aneuk syahi membantu menghaluskan kalimat-kalimat syair yang dilantunkan oleh para Syekh dan penari.

Syekh merupakan pemimpin yang lumrah untuk mengubah syair sesuai dengan kondisi pertunjukan, seperti munculnya syair baru secara mendadak, misalnya disebabkan hadirnya Gubernur sebagai tamu undangan dalam pertunjukan. Contoh Syekh dan penari melantunkan syair yang bertemakan pemerintahan (Sulaiman Juned, 2000:93):

Selama Syamsuddin Mahmud kajeuet keu Gubernur

[Selama Syamsuddin Mahmud menjadi Gubernur]

Leu that pembangunan takalon nyata

[Banyak pembangunan kita lihat nyata]

Jalan pih kaget gedong kamanyang

[Jalan bagus-bagus gedung menjulang tinggi]

Keunoe le datang pariwisata

[Datanglah kesini wahai para wisatawan].

Jika dilihat pada syair di atas, maka terlihat proses munculnya syair yang secara dadakan menjadikan syair yang tidak bisa sepenuhnya maksimal mengadaptasikan pesan ke dalam sebuah struktur syair Aceh yang memiliki persajakan ganda. Maka, $A$ neuk syahi harus langsung mengambil peran untuk menghaluskan kalimat-kalimat yang terdapat pada syair dengan sanjungan seperti berikut:

\footnotetext{
Seulawet Pak Syam yang pimpinan

[Semasa Pak Syam yang menjadi pimpinan]

Leu pembangunan takalon nyata

[Banyak pembangunan terlihat nyata]

Jalan pih kaget leucen kon wayang

[Jalan pun bagus licin sekali]

Inggreh ngon Ceupang keunoe dum teka
} 
[Wisatawan pasti datang kemari].

Seperti layaknya kriteria menjadi seorang Syekh, wawasan dan spontanitas wajib dimiliki oleh Aneuk syahi agar tidak kehabisan ide dan akal untuk berkolaborasi dengan Syekh yang juga harus memunculkan ragam gerak baru sesuai dengan situasi pertunjukan. Jadi, Aneuk syahi harus mampu menjiwai dirinya dengan tempo gerakan penari, karena Syekh dapat mengimbangi vokalnya dengan kecepatan gerak sebab ia juga ikut bergerak dan merasakan ketukan kakinya, sedangkan Aneuk syahi yang berada diluar posisi pola lantai penari hanya bisa melihat dan mendengar, sehingga penting adanya penyatuan gerak dan syair dalam diri Aneuk syahi agar dapat mengetahui dimana ketukan kaki penari akan jatuh dan menyeimbangi kecepatan tempo gerak tari.

\section{c. Peran dan Kedudukan Apiet}

Apiet adalah wakil atau orang yang membantu Syekh dalam pertunjukan tari. Posisi Apiet biasanya berada di kiri dan kanan Syekh pada barisan depan. Peran Apiet adalah mengkoordinir anggota penari lainnya apabila Syekh ke luar barisan. Suatu waktu Syekh dapat keluar barisan dan berputar sendiri menjelajahi seluruh arena panggung untuk mempelajari kondisi arena pertunjukan, seperti memantau tamu atau penonton yang hadir, atau memberikan jeda Syekh untuk berkreativitas memunculkan gerak dan syair yang baru. Pada situasi ini, Apiet langsung mengambil peranan untuk memimpin tari. Selain itu, tugas Apiet adalah memperjelas dan menerjemahkan gerakan yang dilakukan Syekh, apabila Syekh melakukan kekeliruan terhadap gerak yang ada. Misalnya, pada babak Seudati ketika melakukan gerak jak gedhet, pada hitungan kelima Syekh akan berputar ke kanan. Peran Apiet di sini memperjelas gerakan Syekh dengan menjabarkan gerakan jak gedhet menjadi $2 \times 4$ hitungan lalu berputar kekanan. Pada beberapa babak, para penari terkadang lebih fokus terhadap Apeit.

Pada babak Saman, Apiet terbagi dua, yaitu Apiet uneun berada di posisi barisan paling ujung sebelah kanan, dan Apiet wie berada di posisi barisan paling ujung sebelah kiri. Kedua Apiet pada babak ini, sangat berperan dalam menjaga keseimbangan formasi penari lainnya. Misalnya, ketika semua penari yang duduk sebaris memiringkan badannya ke kanan, seorang Apiet uneun harus membuka lututnya sebelah kanan menjadi lebih lebar dari pada posisi sebelumnya untuk menahan berat badan dan menjaga keseimbangan seluruh tubuh penari. Demikian juga ketika semua penari miring ke kiri, Apiet wie langsung membuka lutut kirinya menjadi lebih lebar untuk menahan berat badan penari lainnya agak tidak jatuh, sehingga berapa pun jumlah penari maka semua berat badannya akan ditahan dengan lutut seorang Apiet.

Dari tiga tokoh kepemimpinan dalam tari Rampoe dapat ditarik benang merah, yaitu Syekh merupakan seorang inovator yang memiliki kebijakan dalam bergerak, menciptakan gerak atau syair yang baru yang tergantung pada setiap kondisi pertunjukan. Aneuk syahi merupakan seorang motivator, dalam arti setiap apa yang dilakukan oleh Syekh, Aneuk syahi harus mampu memahami dan menerjemahkan maksud dari tindakan Syekh, tanpa mengubah makna dari ungkapan syair yang diucapkan Syekh. Apiet merupakan seorang eksekutor, di mana seorang Apiet dapat melaksanakan gerak-gerak sesuai dengan instruksi dari Syekh dan menjaga keseimbangan para penari lainnya.

Jika kita lihat bentuk kepemimpinan yang ada di dalam tari Rampoe, maka muncul pertanyaan dari peneliti, dari mana asal usul bentuk kepemimpinan yang ada pada tari. Apakah adanya korelasi dari bentuk kepemimpinan tari dengan jejak struktur pemerintahan adat Aceh. Apabila dikaitkan 
dengan jejak pemerintahan lama, terdapat tiga lembaga kepemimpinan tertinggi di Aceh, yaitu sultan, ulama, dan uleebalang.

Kejayaan kekuasaan sultan-sultan Aceh banyak diakui oleh para pengarang buku dari luar, seperti Wilfred C. Smith seorang pengarang buku Islam in Modern History dalam Thamrin dan Mulyana (2008:85) yang menyatakan bahwa dalam abad XVI terdapat lima besar kerajaan Islam di dunia, yaitu: Kerajaan Turki Ustmani di Asia Kecil, Kerajaan Maroko di Afrika Utara, Kerajaan Agra di India, Kerajaan Isfahan di Persia, dan Kerajaan Aceh Darussalam di Asia Tenggara. James Warren Gold, guru besar di Clarremont College, California USA (1960), menyatakan bahwa di antara sekian banyak kerajaan di Nusantara, Aceh adalah satu-satunya yang menolak keinginan para pendatang Eropa membangun benteng di dalam daerah kekuasaannya untuk tempat pemukiman orang Eropa, pergudangan bagi aneka komoditas yang dibeli saudagar lokal, serta sekaligus menjadi benteng pangkalan militer (Thamrin dan Mulyana, 2008:85).

Dari beberapa pendapat para ahli di atas, dapat kita lihat salah satu bentuk kejayaan kerajaan Aceh Darussalam berkat dipimpin oleh sultan dan sultanah terbaik yang memiliki prestasi tinggi diukur dari keberhasilan kinerja mereka, seperti: menyatukan beberapa kerajaan kecil di satu wilayah, memperluas kerajaan ke wilayah yang lebih jauh, meningkatkan perekonomian wilayah, meningkatkan hubungan internasional dan global, memajukan kebudayaan daerah, melakukan peperanganpeperangan besar, sehingga menunjukkan keberanian yang luar biasa dalam menentang upaya pendudukan dan penjajahan.

Uleebalang adalah raja-raja kecil yang membantu sultan dalam mengurus pemerintahan di wilayah beberapa mukim, serta penghubung antara rakyat, geuchik (kepala kampung), Tuha Peut (ketua adat) dan sultan. Uleebalang juga sebagai panglima tentara yang menjalankan perintah sultan berkenaan dengan adat dan agama. Menurut Syaikh Ibnu Abbas dalam Alfian (1987: 41) uleebalang bertugas menjaga ketertiban umum yang diatur oleh adat.

Ulama merupakan sosok pemimpin yang sangat berperan penting dalam menjaga keutuhan sistem pemerintahan kerajaan Aceh. Karena sultan merupakan pemimpin adat, sedangkan adat harus disusun sesuai dengan agama yang berdasarkan Al-Quran, hadis, ijma, dan qiyas, maka ulama yang merupakan ahli di bidang tersebut sangat dibutuhkan peran sertanya. Berdasarkan hal tersebut, sultan mengangkat ulama sebagai penasehat, yang disertai dengan kedudukan struktural sebagai mufti kerajaan (Qadhi Malikul Adil) pada posisi kedua setelah raja. Ulama mengambil peran penting dalam memberikan motivasi, inspirasi, nasehat, bahkan pelaku aksi dalam perang melawan segala bentuk penjajahan. Dibidang politik, ulama menjadi mitra raja dalam mengambil kebijakan. Titah raja sebagai adat yang dilandasi sebagai syariat, sehingga tidak boleh ada adat yang berlainan dengan syariat.

Peran ulama yang membantu sultan dalam melaksanakan pemerintahan tercatat dalam Undang-undang Qanun Al-asyi Meukuta Alam (Adan, 2014: 132) yang menerangkan:

"Ulama dengan raja atau Rais tidak boleh
jauh atau bercerai, sebab jikalau bercerai
dengan raja niscaya binasalah negeri. Ba-
rangsiapa mengerjakan hukum Allah dan
meninggalkan adat maka bersalah dengan
dunianya, dan barangsiapa mengerjakan
adat dan meninggalkan hukum Allah maka
berdosalah dengan Allah. Maka hendaklah
hukum dengan adat seperti gagang pedang
dengan mata pedang"

Seiring dengan hal tersebut, Muliadi Kurdi (2010:6) mengatakan Aceh dari masa ke masa dibangun di atas pilar penting, yaitu kekuatan "penguasa" (sultan) dan sumbangan pemikiran "ulama". Kedua 
pilar ini diibaratkan dua sisi mata uang logam yang saling memberikan nilai tambah satu dengan yang lain. Pernyataan tersebut dapat dikaitkan dengan hadih maja Aceh yang berbunyi Adat bak Po Teumeureuhom, Hukom bak Syiah kuala.

Maknanya adalah bahwa kekuasaan eksekutif dan adat istiadat berada di bawah kepemimpinan sultan (Po Teumeureuhom). Kekuasaan yudikatif berlandaskan dengan syariat menjadi tugas Qadhi Malikul 'Adil yang dipegang oleh ulama. Setiap kebijakan sultan selalu disesuaikan berdasarkan Al-quran, Hadist, Qiyas, dan Ijma oleh ulama, sehingga terjadi adanya kolaborasi kepemimpinan antara sultan sebagai pemimpin adat dan ulama sebagai pemimpin hukum agama. Uleebalang sebagai eksekutor atau pelaksana. Apiet di dalam tari Rampoe merupakan orang yang menjalankan instruksi dari syekh dan menjaga keseimbangan badan penari di dalam posisi tari. Uleebalang adalah pelaksana dari kebijakankebijakan sultan serta menjaga ketertiban dan keamana wilayah mukim atau sagoe.

Dari penjelasan mengenai peran dan kedudukan masing-masing para tokoh di atas dapat dilihat bahwa ada keterkaitan antara tiga pola kepemimpinan tersebut dan membuktikan sebuah pernyataan bahwa tari sebagai produk ekspresi, mencerminkan segala tingkah laku, pola pikir, nilai, dan konsep budaya masyarakat yang menyangganya.

\section{SIMPULAN}

Pada penelitian ini ditemukan beberapa karakteristik masyarakat Aceh, sebagai berikut:

a. Tari Rampoe menggambarkan kekompakan.

b. Tari Rampoe menggambarkan karakteristik masyarakat Aceh yang tegas, kukuh dan pantang menyerah.

c. Tari Rampoe menggambarkan karakteristik masyarakat Aceh yang konsisten dengan apa yang menjadi keputusannya.

d. Tari Rampoe menggambarkan karak- teristik masyarakat Aceh yang setia kawan, memiliki solidaritas yang tinggi tetapi juga memiliki sifat tidak mudah memaafkan orang lain.

e. Tari Rampoe menggambarkan pola tatanan masyarakat Aceh yang religius.

f. Terdapat korelasi tiga tokoh kepemimpinan dalam tari dengan struktur pemerintahan adat Aceh, yaitu: (1) Syekh -> Sultan sebagai inovator atau penentu kebijakan; (2) Aneuk syahi -> Ulama sebagai motivator; (3) Apiet -> Uleebalang sebagai eksekutor atau pelaksana.

\section{Daftar Pustaka}

Ahmad Zakaria

2007 Lintas Perjuangan Cut Nyak Meutia, Sosok Pejuang Wanita Aceh. Banda Aceh: Yayasan PeNa.

Edi Sedyawati

1986 “Tari sebagai Salah Satu Pernyataan Budaya" dalam Departemen Pendidikan dan Kebudayaan (Penyunting) Pengetahuan Elementer Tari dan Beberapa Masalah Tari. Jakarta: Departemen Pendidikan dan Kebudayaan.

Essi Hermaliza

2014 Seudati di Aceh. Banda Aceh: Balai Pelestarian Nilai Budaya Banda Aceh.

Hassanuddin Yusuf Adan

2014 Islam dan Sistem Pemerintahan di Aceh Masa Kerajaan Aceh Darussalam, edisi cetakan kedua. Banda Aceh: Yayasan PeNa Divisi Penerbitan.

Ibrahim Alfian

1987 Perang di JalanAllah: Perang Aceh 18731912. Jakarta: Pustaka Sinar Harapan.

I Made Wirartha

2006 Pedoman Penulisan: Usulan Penelitian, Skripsi, dan Tesis. Yogyakarta: C.V. Andi Offset. 
I Wayan Dibia

2007 “Tari Bali dalam Kajian Etnokoreologi" dalam Pramutomo, R.M. (Penyunting). Etnokoreologi Nusantara (Batasan Kajian, Sistematika, dan Aplilikasi Keilmuan). Surakarta: ISI Press.

Muliadi Kurdi

2005 Karakteristik Masyarakat Desa (Pendekatan Sosiologi Budaya dalam Masyarakat Atjeh). Banda Aceh: Yayasan PeNa.

---.

2010 Ulama Aceh dalam Melahirkan Human Resource di Aceh. Banda Aceh: Yayasan Aceh Mandiri.

\section{R. M. Soedarsono}

1986 "Pengantar Pengetahuan dan Komposisi Tari" dalam Departemen Pendidikan dan Kebudayaan (Penyunting), Pengetahuan Eelementer Tari dan Beberapa Masalah Tari. Jakarta: Departemen Pendidikan dan Kebudayaan.

Sal, Murgiyanto

1986 “Dasar-dasar Koreografi Tari”. dalam Departemen Pendidikan dan Kebudayaan (Penyunting), Pengetahuan Elementer Tari dan Beberapa Masalah Tari. Jakarta: Departemen Pendidikan dan Kebudayaan.

Singh, Ranbir, Malik \& Hamied, Fuad, Abdul. 2014 Research Methods: A Gguide for First Time Researchers. Bandung: Universitas Pendidikan Indonesia.
Soemaryatmi

2010 "Pertunjukan Tari Campur Bawur dalam Tradisi Syawalan Desa Lencoh Sela Boyolali" dalam Jurnal Pengetahuan dan Pemikiran Seni Vol 10 No 1.

Sulaiman, Juned

2000 "Masa Depan Seni Tradisional Aceh" dalam Jurnal PALANTA Seni Budaya. Nomor: 8 Thn. IV.

Supriyanto

2012 "Tari Klana Alus Sri Suwela Gaya Yogyakarta Perspektif Joged Mataram" dalam Jurnal Joged Seni Tari, ISSN: 1858-3989 Vol. 3 No. 1 Mei 2012,(hlm.1-16)

Tati Narawati

2007 "Etnokoreologi dalam Kasus Tari Sunda" dalam Pramutomo, R.M (Penyunting). Etnokoreologi Nusantara (Batasan Kajian, Sistematika, dan Aplikasi Keilmuan). Surakarta: ISI Press.

2009 Etnokoreologi sebagai Sebuah Disiplin Kajian Tari. Bandung: Universitas Pendidikan Indonesia.

Tjetjep Rohidi

2011 Metodologi Penelitian Seni. Semarang: Cipta Prima Nusantara.

Thamrin H.M. \& Edi Mulyana

2008 Leburnya Provinsi Aceh. Aceh: Badan Arsip dan Perpustakaan. 